similar to that of cholinesterase activity ${ }^{8-4}$. According to Nachmansohn and Lederer", cholinesterase also contains free sulphydryl groups. The reaction described above does not take place, however, if the muscle is frozen or incubated in distilled water before treatment with lead nitrate, though neither treatment affects cholinesterase activity. It seems very likely, therefore, that reaction with lead is not due to cholinesterase, but to a substance of a smaller molecular weight, having the same cytological localization as cholinesterase, such as cysteine, methionine or glutathione. The role taken by these $-\mathrm{SH}$ com. pounds in the synthesis of acetylcholine and in the transmission of impulses may offer an explanation for the myoneural-synaptical localization of the reaction.

\section{Gy. SAvay}

B. CsILlik

Institute of Anatomy and Histology, Modical University, Szeged, Hungary. Jan. 15.

1 Koshtoyantz, H. S., 19th Internat. Physiol. Congr., Montreal, 1953. 2 Gerebtzoff, M. A., Acta Anat., 19, 366 (1953).

sávay, Gy., and Csillik, B., Acta Morph. Ac. Sci. Hung., 6, 289 (1956). - Csillik, B., and Sávay, Gy., Acta Neurovegetativa (in the press).

s Nachmansohn, D., and Ioderer, E., C.R. Soc. Biol., Paris, 180, 321 (1939); Bull. Soc. Chim. Biol., 21, 797 (1939).

\section{Failure of the Agglutination Test to identify Types of Pasteurella multocida}

A NUMBer of different serological methods have been employed for the identification of types within the species Pasteurella multocida ${ }^{1-8}$. Three different serological types were identified by Little and Lyon ${ }^{4}$ by means of a slide agglutination test. Their types 1 , 2 and 3 were made available through the American Type Culture Collection. These and other types identified by Little and Lyon's technique have been employed in some recent studies on $P$. multocida $a^{5-7}$. It is the purpose of this communication to point out inadequacies of the agglutination test for the identification of serological types within this species.

Different types of $P$. multocida can be recognized by an indirect hæmagglutination test ${ }^{8, \theta}$ in which the specific capsular substance is employed as antigen and by mouse protection tests in mice ${ }^{10}$. The results of the hæmagglutination test concur with those obtained with the serum protection tests.

A large number of slide and tube agglutination tests have been carried out with a variety of strains of $P$. multocida over a number of years. It has not been possible to identify types with any degree of confidence by the agglutination reaction. Two of the reasons for the deficiency of these tests are cited below.

Many capsulated strains of $P$. multocida, partic. ularly freshly isolated strains, are inagglutinable in low dilutions of their homologous immune sera, although they may give reactions as high as $1: 320$ and $1: 640$ in the hæmagglutination test. The A.T.C.C. strain No. 6535 (type 3) was negative to all four type sera in the tube agglutination test. The A.T.C.C. strain No. 6530 (type 2) was agglutinated only partially by types $A$ and $B$ antisera.

Many non-capsulated strains of $P$. multocida produce smooth colonies and possess high mouse virulence. In a previous study these cultures were referred to as colonially smooth but antigenically rough. Among these cultures are many that clump to a varying degree in the presence of sodium chloride. The difficulty of carrying out satisfactory agglutination tests with these cultures has been referred to ${ }^{3}$. The A.T.C.C. strain No. 7707 (type 1) was so sensitive to salt that the majority of organisms settled out of saline in less than $24 \mathrm{hr}$.

Because of inagglutinability due to capsulation, and spontaneous clumping in the presence of sodium chloride, I have found the agglutination tests to be unreliable in the identification of serological types. Until the difficulties cited above have been circum. vented, it is recommended that the use of the serological classification of Little and Lyon be suspended.

The perpetuation of an unsound serological classification will only contribute to confusion in an already complex and little-understood species. For example, the conclusions reached in a recent study ${ }^{11}$ of $P$. multocida will remain in question as long as there is doubt regarding the identification of the type strains employed.

\section{G. R. Carter}

Ontario Veterinary College, Guelph, Canada. Feb. 10.

1 Cornelius, J. T., J. Path. Bact., 32, 355 (1929).

Yusef, H. S., J. Path. Bact., 41, 203 (1935)

Rosenbusoh, C. T., and Merchant, I. A., J. Bact., 87, 69 (1938).

'Little, P. A., and Lyon, B. M., Amer. J. Vet. Res., 4, 110 (1943).

${ }^{5}$ Yaw, K. E., Briefman, L., and Kakovas, J. C., Amer. J. Vet. Res. 17, 157 (1956).

'Sinha, S. K., Tachibana, T. F., and Fagan, R., Cornell Vet., 47, 281 (1957).

7 Iondon, S. A., and Yaw, K. E., Can. J. Microbiol., 3, 1021 (1957).

- Carter, G. R., Amer. J. Vet. Res., 16, 481 (1955).

- Carter, G. R., Amer. J. Vet. Res., 18, 437 (1957).

${ }^{10}$ Roberts, R., J. Comp. Path., 57, 261 (1947).

1 Carter, G. R., Amer. J. Vet. Res., 18, 210 (1957).

\section{Lingering Effects of Local X-Irradiation on Healing of Burns}

X-RAYS delay the healing of thermal burns and other injuries ${ }^{1-4}$. What is not well known is how long the inhibitory action of X-rays lasts. The present experiment was designed to determine the length of time this inhibitory effect persists in a locally irradiated area so as to retard the healing of subsequent thermal burns.

$X$-rry doses of 1,600 and $2,400 \mathrm{r}$. were used, and the thermel burns inflicted immediately and one, two and three weeks after irradiation. Doses lower than $1,600 \mathrm{r}$. produced either inconsistent or no effects on burn hesling. Ten rats weighing 250-350 gm. were used for each condition; there being 80 in the whole experiment. 2,000 kVp. X-rays were administered at a rate of $600 \mathrm{r} . / \mathrm{min}$. to an area on the flank and upper hind leg in a half-moon shape 1 in. in diameter. The remainder of the body was shielded from the radiation by $4 \mathrm{in}$. of lead. The animals were lightly anresthetized with nembutal. One day before the irradiation the area was freed of hair by clippers followed by a depilatory lotion and washing. Animals were burned with a heated copper brand $\left(200^{\circ} \mathrm{C}.\right)$ in the form of three parallel lines (1/32 in. wide, $1 \mathrm{in}$. long and 3/16 in. apart) placed on the skin for 1 sec. so that one-half of all three branding lines were in the irradiated area and the other half of the three brands in the adjacent non-irradiated area. Daily observations for differences in the heeling of these 